\title{
La Tasa de Miseria de los Hogares. Una aproximación metodológica y conceptual a la medición, distribución espacial y variaciones de la pobreza extrema en Argentina durante la década del noventa Misery Rate of Homes. A methodological and conceptual approximation to measuring spatial distribution and variations of extreme poverty in Argentina during the decade of the nineties
}

\author{
Fernando Longhi*
}

\section{INTRODUCCIÓN}

El estudio de la pobreza ha sido abordado en numerosos trabajos procedentes de distintas disciplinas. Así, desde la economía se desarrollaron principalmente métodos econométricos para la medición de la pobreza; desde la sociología y la antropología se profundizó en la conceptualización del fenómeno y en el estudio de las estrategias de supervivencia de las familias pobres; desde la epidemiología se estudió el impacto que en la salud generan determinadas condiciones de vida precaria, etc. No obstante, el problema del análisis de la distribución espacial de la pobreza y su evolución no ha tenido un interés principal ${ }^{1}$.

* Becario Posdoctoral. Instituto Superior de Estudios Sociales (CONICET - UNT), San Miguel de Tucumán. Argentina (fernandolonghi@hotmail.com).

${ }^{1}$ El problema de la distribución espacial ha ocupado un lugar primordial dentro de los estudios geográficos. Un geógrafo clásico como Carl Sauer sostiene que «la ubicación de los fenómenos en el espacio expresa el problema geográfico central de la distribución, y nos lleva a 
En Argentina, la información necesaria para identificar la pobreza y definir su distribución espacial ha sido relevada en los Censos Nacionales a partir del año 1980. Con esta información es posible realizar mapas de pobreza con una alta capacidad de desagregación geográfica, alcanzando en este caso la unidad espacial mínima, es decir el radio censal, sin llegar con ello a violar la disposición del secreto estadístico. El método utilizado en tales mediciones correspondía con el de las Necesidades Básicas Insatisfechas (NBI), no obstante, estudios actuales han puesto de manifiesto las limitaciones de dicho método para mostrar las actuales manifestaciones de la pobreza².

Como resultado de dichas limitaciones surgieron propuestas que plantean modificaciones y procuran superar las deficiencias señaladas. Se destaca el Índice de Privación Material de los Hogares (IPMH), una herramienta elaborada por el Instituto Nacional de Estadísticas y Censos (INDEC), el cual supera las limitaciones inherentes al método NBI. No obstante su aplicación solo es posible en el año 2001 debido a las características de las variables incluidas en los censos.

En este trabajo se tomó como eje principal la comparación. Por tal motivo se pretendió generar una herramienta de medición de la pobreza que permita tal proceso y, a la vez, mantenga relación con el IPMH. La elaboración de la Tasa de Miseria de los Hogares logró solucionar este problema y brindó, mediante su aplicación, respuestas referidas al dónde la pobreza alcanza las mayores magnitudes y las variaciones de esa distribución en el transcurso de la década del noventa.

preguntar acerca del significado de la presencia o ausencia, agrupamiento o dispersión de cualquier cosa o grupos de cosas en lo que respecta a extensión de área. En el sentido más estricto, el método geográfico se ocupa de examinar la localización sobre la Tierra de cualquier fenómeno. Los alemanes han llamado a esto el standortsproblem —el problema de la posición terrestre- y representa la expresión mas general y más abstracta de nuestra tarea» (Sauer 1941, p. 4). En este sentido, podemos afirmar que no es posible estudiar fenómeno social alguno sin considerar su distribución espacial. Afirman en este sentido Tissot y Poupeau (2005) que la cuestión de la pobreza no puede ya ser dicha, descripta y discutida de otro modo que no sea en un registro espacial y con la ayuda de categorías territoriales.

2 Entre otras limitaciones se ha señalado que la cantidad de pobres que se identifica depende de la cantidad de indicadores que se utilizan para definir la población con NBI (Gómez, Mario y Olmos, 2003), el método NBI solo ha identificado grupos poblacionales aquejados de carencias extremas de tipo estructural (Álvarez, 2002), no es posible la distinción de grados de satisfacción de necesidades, considerando a la pobreza como un fenómeno único y homogéneo solo susceptible de una clasificación dicotómica: pobre/no pobre (Gómez, Mario y Olmos, 2003), no es posible el reconocimiento de la población afectada por los procesos de empobrecimiento de los últimos años debido al carácter estructural de las carencias identificadas (Kaztman, 1996). Asimismo el indicador de capacidad de subsistencia refleja escasamente la insuficiencia de ingresos (Álvarez, 2002). 


\section{Los alcances del concepto de pobreza}

La pobreza ha sido asociada frecuentemente con conceptos como nivel de vida, desigualdad, marginalidad, vulnerabilidad, exclusión, etc., las cuales constituyen distintas manifestaciones del fenómeno con distintos alcances que son necesarios diferenciar.

El nivel de vida fue uno de los primeros antecedentes en los estudios de pobreza. Surgió en el seno de Naciones Unidas como un concepto que procuraba detectar las «condiciones reales en que vive un pueblo» (Naciones Unidas, 1961). Procuraba delimitar condiciones que pudieran representarse cuantitativamente y que reflejasen objetivos económicos y sociales aceptados por la política internacional. Se definieron entonces componentes del nivel de vida como salud, consumo de alimentos y nutrición, educación, empleo y condiciones de trabajo, vivienda, seguridad social, vestido, esparcimiento y libertades humanas. Estos componentes marcaron los primeros antecedentes respecto a los actuales estudios sobre pobreza, evidenciando de alguna manera la heterogeneidad de los componentes incluidos.

En cuanto a la desigualdad, si bien el estudio de la pobreza se vincula a este, existen según Gasparini, Marchionni y Sosa (2000) dos diferencias conceptuales importantes:

- Mientras un estudio de desigualdad evalúa la distribución de los recursos en toda la población, un estudio de pobreza solo estudia el sector más desfavorecido en tal distribución.

- Asimismo, mientras el concepto de desigualdad es relativo, la pobreza tiene a menudo elementos absolutos. Por ejemplo, una duplicación de los ingresos de todos los habitantes de un país no modifica las medidas habituales de desigualdad, pero reduce las medidas usuales de pobreza medidas por el nivel de los ingresos.

El concepto de marginalidad surge en el decenio de 1960 para denotar a los grupos poblacionales que migran del campo y rodean las principales metrópolis latinoamericanas con un cinturón de pobreza. Según Nun (1969), la población marginal pasó a ser caracterizada como carente de infraestructura, de oportunidades educacionales y de empleo, constituyendo un ejército de reserva de mano de obra, funcional para la economía, porque su presión por puestos de trabajo tendería a hacer bajar los salarios de los obreros. Al comienzo se llamó marginales a los asentamientos urbanos periféricos (villas miseria, callampas, favelas, rancheríos, etc.) que proliferaron sobretodo a partir de la segunda posguerra. Estos se caracterizaban por la presencia de vivien- 
das situadas al borde las ciudades y carentes de ciertos requisitos mínimos de habitabilidad. Implicaba así otros dos significados: el de un centro urbano en relación con el cual se caracterizaba lo periférico y respecto de cuyas condiciones habitacionales medias se juzgaban aquellas carencias.

Precisamente este último aspecto fue el que llevó a extender el uso de la noción, al advertirse que albergues no periféricos (conventillos, cités, callejones, vecindades, etc.) padecían deficiencias iguales o peores que las de esos asentamientos. Por lo tanto, se relegó a un segundo plano la localización física de la vivienda y la marginalidad pasó a referirse a los rasgos negativos propios de esta última (Nun, 2001).

La vulnerabilidad se relaciona con dos dimensiones: una externa y objetiva que se refiere a los riesgos externos a los que puede estar expuesta una persona, familia o grupo (mayor inestabilidad de los ingresos familiares, aumento de la precariedad en el mercado de trabajo reflejado en porcentajes crecientes de personas empleadas con contratos no permanentes o sin contratos, etc.); y otra dimensión interna y subjetiva, que se refiere a la falta de recursos para enfrentar esos riesgos sin sufrir ciertas pérdidas (Arriagada, 2005).

La exclusión social en tanto, se refiere a la falta de lazos que vinculen al individuo con la familia, la comunidad, la sociedad; y a la carencia de derechos básicos de ciudadanía. Tales lazos pueden ser de tipo familiar, institucional o cultural (Arriagada, 2005). Este concepto nace en Europa, donde la realidad social era muy diferente a la latinoamericana. Los excluidos eran allí quienes habían quedado a la vera del camino del progreso general, es decir los inadaptados (Nun, 2001).

Un concepto sobre el que se han venido realizando importantes investigaciones en los últimos años y que trata de dimensionar las carencias de la población es el de la calidad de vida. Tal concepto procura identificar aspectos objetivos y subjetivos del bienestar de las personas. Sostienen referentes del estudio de la calidad de vida: «la pobreza es una medida de carencia de quienes no llegan a alcanzar un umbral mínimo establecido. La calidad de vida, en cambio, es una medida de logro respecto de un nivel establecido como óptimo teniendo en cuenta dimensiones socioeconómicas y ambientales dependientes de la escala de valores prevaleciente en la sociedad y que varían en función de las expectativas de progreso histórico» (Velázquez, 2001, p. 15). El concepto de calidad de vida supone, entre otras cosas, llevar una vida larga y saludable; tener educación y disfrutar de un nivel de vida decente; gozar de libertad política y acceder a una serie de derechos inherentes a los individuos; tener acceso a un trabajo digno y bien remunerado y participar en la vida comunitaria. Las dificultades para medir o cuantificar esas variables, han restringido su estudio 
hacia los aspectos más fácilmente cuantificables — generalmente los materiales- que se relacionan con lo que se denomina «nivel de vida».

De esta manera los conceptos de nivel de vida, marginalidad, exclusión social, desigualdad y calidad de vida son conceptos tangenciales al fenómeno de la pobreza y ponen de manifiesto las múltiples manifestaciones de la pobreza y por consiguiente, lo dificultoso que se torna su conceptualización y más aun su medición.

En efecto, la medición de la pobreza no es una cuestión, en absoluto, separada del concepto de pobreza. Para identificar y medir la pobreza los estudios fijan habitualmente la atención en las privaciones severas de bienes y servicios que una parte variable de la población sufre debido a sus magros ingresos (Ferullo, 2009); no obstante plantea Sen (1997) que confiar exclusivamente en la pobreza en términos de ingreso puede esconder aspectos cruciales de la privación económica. Sen centra su atención en las potencialidades de la gente y en las condiciones que restringen la libertad de tener lo que cada uno considera racionalmente que vale la pena ser y tener. Así, la condición de pobreza de una persona se corresponde con algún grado de privación que le impida el desarrollo pleno de sus capacidades, y en última instancia de su libertad (Ferullo, 2009) ${ }^{3}$. El enfoque basado en las capacidades humanas planteado por Sen contribuye de manera significativa a «comprender mejor la naturaleza y causa de la pobreza y la privación, trasladando la atención principal de los medios (y de un determinado medio que suele ser objeto de atención exclusiva como la renta) a los fines que los individuos tienen razones para perseguir y por lo tanto, a las libertades necesarias para satisfacer estos fines» (Sen 2000, p. 117).

El aporte de Sen ha sido fundamental para entender la pobreza como un fenómeno multidimensional en el que deben necesariamente considerarse dimensiones no monetarias. Según el enfoque iniciado por Sen no son los medios (ingresos o gastos) los que cuentan sino los resultados en términos de bienestar y condiciones de vida (mortalidad, analfabetismo, esperanza de vida, etc.). Sen define por tanto la pobreza como la privación de capacidades, entendidas como habilidades para alcanzar ciertas condiciones de vida, por lo tanto la conexión con la insuficiencia de ingresos es solo instrumental.

\footnotetext{
${ }^{3}$ Plantean igualmente Córdoba Ordóñez y García Alvarado (1991) que la pobreza define una situación carencial en un contexto vital del ser humano y probablemente sea simplista reducir este a su componente económico, pero es indudable que en un sistema como el nuestro, de filosofía utilitarista y práctica consumista, cada situación carencial en el marco vital debe asociarse a una deficiente disponibilidad material que, en consecuencia, debe estar en la base de cualquier definición de pobreza.
} 
No existen marcos conceptuales que expliquen satisfactoriamente el problema de la pobreza en su totalidad (Altimir, 1979) ${ }^{4}$; no obstante, en nuestro trabajo concebimos que la pobreza alude siempre a una situación en que se encuentran las familias o un grupo de ellas. Esta situación no es la suma o el agregado mas o menos independiente de dimensiones o aspectos parciales, sino el cuadro situacional estructural en el que se hallan determinadas familias, producto de su particular inserción en la estructura socioproductiva, siendo esta la que determina la posibilidad de no acceder o, de acceder en mayor o menor medida, a determinados bienes y servicios (Moreno 1995). La pobreza se manifiesta mediante algunas características generales de las familias pobres tales como sus bajos niveles educacionales, insuficiencias nutricionales, y una menor participación relativa en la actividad laboral, lo que se define a su vez por una pertenencia a ocupaciones de la más baja productividad, que generan escasos ingresos y que impiden satisfacer integralmente sus necesidades más esenciales, materiales y no materiales. Así, el concepto de pobreza se encuentra atravesado por tres matices diferentes: la idea de carencia de recursos, bienes y servicios; la idea de insatisfacción de aquellas necesidades que una sociedad o grupo social satisfacen en su globalidad; y la idea de marginalidad o exclusión de aquellos recursos, bienes y servicios que puedan ser compartidos en una sociedad.

Los aspectos materiales de la pobreza han mantenido el protagonismo en los estudios sobre la temática. No obstante, los aspectos no materiales en la conceptualización de la pobreza han tomado un interés particular los últimos años. En este sentido, González (1997, p. 285) define a la pobreza como un fenómeno multidimensional, que se refiere a la «privación de medios de vida y pérdida de estirpe». Esta definición tiene la ventaja de no pertenecer a ningún cuerpo teórico en particular y tiene a su alcance la posibilidad de ingresar problemáticamente en los más diversos ordenamientos conceptuales. No obstante las fuentes de información para estudiar los aspectos no materiales de la pobreza, tales como la pérdida de estirpe, son escasos y limitados solamente a encuestas de poblaciones relativamente pequeñas. De este modo, los aspectos materiales en la medición de la pobreza continúan rigiendo actualmente los enfoques y los estudios.

\footnotetext{
${ }^{4}$ La propia falta de precisión teórica del concepto de pobreza impide también considerar a los pobres como un grupo social estricto, y la naturaleza descriptiva del concepto solo permite, en principio, considerarlo como una categoría social clasificatoria que funciona como un agregado estadístico (Moreno, 1995).
} 


\section{Enfoques de pobreza}

Dentro de la bibliografía existen dos grandes enfoques sobre la cuestión de la pobreza: una aproximación subjetiva y una objetiva. El enfoque subjetivo define a la pobreza como una sensación individual dependiente de las preferencias y consideraciones de cada individuo y de lo que este juzgue necesario para tener un nivel adecuado de vida ${ }^{5}$. Este enfoque se distingue de la aproximación objetiva, la cual tiene como punto de partida la explicitación de criterios únicos que el investigador utiliza para identificar a los pobres (Reyes Romano, 1996).

Dentro del enfoque de pobreza objetiva existen dos aproximaciones conceptuales en relación a esta: relativa y absoluta. La aproximación relativa plantea que las necesidades que se consideran esenciales para vivir una vida digna varían en el tiempo y en el espacio de acuerdo con los valores de las distintas sociedades; según los partidarios de estas líneas las necesidades de la vida no son fijas, continuamente están siendo adaptadas y aumentadas conforme ocurren cambios en la sociedad (Boltvinik, 1990). De este modo, pueden llegar a ser rotundamente diferentes las características de un hogar pobre en un país desarrollado y en uno subdesarrollado.

La aproximación absoluta subraya la imposibilidad de acceder a un nivel de satisfacción necesario para la existencia y reproducción de la sociedad. Destaca asimismo la imposibilidad de alcanzar niveles nutricionales adecuados para lograr un crecimiento psico-físico considerado normal, sin importar diferencias espaciales o temporales. Los seguidores de esta línea manifiestan que hay un núcleo irreducible de privación en la idea de pobreza que se traduce en muertes por hambre, desnutrición y penuria, visibles en un diagnóstico de pobreza sin tener que indagar primero el panorama relativo (Sen, 1978).

Señala Sen (1983, citado por Boltvinik, 1990) que no se trata de enfoques excluyentes, sino de algún modo complementarios. Por lo tanto puede considerarse un carácter absoluto de la pobreza en cuanto a los requerimientos mínimos y un carácter relativo en relación no a las necesidades, sino a los satisfactores de esas necesidades y su variación espacio-temporal.

${ }^{5}$ El estudio de la pobreza subjetiva constituye un campo muy poco analizado hasta el momento. Sostiene Giarrizzo (2007) que dicha manifestación de la pobreza incluye a aquellas personas cuyos ingresos superan el monto mínimo de subsistencia, pero a pesar de ello se perciben y definen a si mismos como pobres; dichas personas se sienten pobres por no poder alcanzar el nivel de vida que desean, que en general incluye el acceso a productos y servicios vinculados con la vivienda, la educación, la salud y la tecnología, o por haber perdido el nivel de vida que tuvieron en periodos anteriores. Para mas detalle sobre esta manifestación de la pobreza en el caso argentino ver Giarrizzo (2007). 
Según las características de las privaciones se ha definido una pobreza estructural diferenciada de una pobreza coyuntural. La primera tiende a corregirse con el crecimiento económico y la evolución de otros parámetros dependientes de este: cultura, educación, etc.; la pobreza coyuntural en cambio es un problema esencialmente económico en el cual los ingresos de los hogares se ven afectados inscribiéndose en el universo de la pobreza. Cuando la crisis económica más se prolonga en el tiempo corre el riesgo de convertir a los pobres coyunturales en pobres estructurales.

\section{Pobreza absoluta y miseria}

Dentro de la idea de pobreza absoluta subyace la idea de pobreza extrema o miseria, entendida como aquella situación que denota la insatisfacción de necesidades mínimas y vitales para la supervivencia. ${ }^{6}$

A partir del Diccionario de la Real Academia Española (RAE) 22. ${ }^{a}$ edición ${ }^{7}$ se exploraron los conceptos de pobreza y miseria. Tal diccionario define a la 'pobreza' como 1. cualidad de pobre; 2. falta, escasez; 3. dejación voluntaria de todo lo que se posee, y de todo lo que el amor propio puede juzgar necesario, de la cual hacen voto público los religiosos en día de su profesión. La 'miseria' es definida en su $2 .^{a}$ acepción como estrechez, falta de lo necesario para el sustento o para otra cosa, pobreza extremada. Esta última acepción justifica el uso del término arriba mencionado.

Con el concepto de miseria ingresamos al campo conceptual sobre la tesis de las necesidades mínimas para la supervivencia, y en este caso son insoslayables los aportes realizados por los trabajos clásicos de Maslow (1954) y su teoría de las necesidades. En efecto, para este autor las necesidades del ser humano están jerarquizadas y escalonadas de forma tal que cuando quedan cubiertas las necesidades de un orden es cuando se empiezan a sentir las necesidades del orden superior. Tal autor identifica cinco niveles de necesidades dentro de la jerarquía:

1. Fisiológicas: constituyen la primera prioridad del individuo y se encuentran relacionadas con su supervivencia. Dentro de estas encontra-

\footnotetext{
${ }^{6}$ Plantea Boltvinik (1990) que lo necesario para sustentar la vida no es lo superfluo ni lo contingente. Por lo contrario es algo sobre lo cual no podemos ejercer nuestra libertad, puesto que es algo de lo cual nos es imposible sustraernos.

${ }^{7}$ En línea: http://www.rae.es/rae.html (consulta 15 de marzo de 2007).
} 
mos la alimentación, agua, mantenimiento de una temperatura corporal adecuada, entre otras.

2. Seguridad: se relacionan con la tendencia a la conservación frente a situaciones de peligro. Incluye conservación de propiedad, empleo, etc.

3. Sociales: plantea que el hombre por naturaleza tiene la necesidad de relacionarse, de agrupase informalmente, en familia, con amigos, o formalmente en las organizaciones.

4. Estima: en esta altura de la pirámide el individuo necesita algo mas que ser miembro de un grupo, se hace necesario recibir reconocimiento de los demás en términos de respeto, status, prestigio, poder, etc.

5. Autorrealización: consiste en desarrollar el máximo potencial de cada uno. Son ejemplos de ella la autonomía, el autocontrol, la independencia.

La pobreza extrema o miseria estaría relacionada con la insatisfacción del primer escalón de la pirámide de Maslow, es decir el referido a la insatisfacción de necesidades vitales. La miseria guardaría relación fundamentalmente con el hambre y la desnutrición, como así también con el acceso al agua potable, a una vivienda que permita mantener la temperatura corporal mínima necesaria para la vida, abrigo, mantenimiento de niveles de higiene óptimos para asegurar el no contagio de enfermedades infecciosas, etc. En este sentido, plantean Romero González y Pérez Esparcia (1992, p. 73) que «no es casual que las zonas con mayor número de pobres sean también aquellas en las cuales el consumo de calorías y proteínas es más reducido». Asimismo, la falta de nutrientes y desnutrición incrementa la frecuencia, gravedad, y la duración de las infecciones, derivando con ello en un aumento de la mortalidad.

El hambre, entendido como el principal indicador de la miseria es definido por Josué de Castro (1962) como un asunto tan delicado y peligroso por sus implicancias políticas y sociales que permanece aun como uno de los tabúes de nuestra civilización ${ }^{8}$. Este autor desestima la teoría maltusiana al definir al hambre no como un problema de limitación, sino como un problema de distribución (Castro 1962, p. 48), no determinado por factores de orden natural, sino de orden social (Castro 1962, p. 146) ${ }^{9}$.

${ }^{8}$ No obstante, el hambre no es solo el resultado de una insuficiente cantidad de comida, sino también de su baja calidad (Altvater, 2007).

${ }^{9}$ Malthus en sus estudios clásicos sobre población y recursos afirmaba el ritmo diferencial del crecimiento de ambas dinámicas. Esta situación de desequilibrio requiere la aplicación de frenos maltusianos. No obstante, desde la teoría de Boserup, este desequilibrio puede redundar en un desarrollo de nuevas tecnologías, lo cual evita la aplicación de los mencionados frenos y 
La medición de la pobreza extrema

La medición de la pobreza debe incluir necesariamente en su formulación dos pasos:

1. Un método para incluir a un grupo de personas en la categoría de pobres (identificación), y

2. Un método para integrar las características del conjunto de pobres en una imagen global de la pobreza (agregación) (Sen 1992).

La identificación consiste en definir un conjunto de necesidades básicas o mínimas y considerar la incapacidad de satisfacer estas necesidades como prueba de pobreza, en cambio la agregación se refiere al modo de representar la pobreza en determinada área geográfica.

Asimismo Kaztman (1996) plantea la existencia de cinco criterios que deben cumplir los indicadores de medición de la pobreza: agregación geográfica, representatividad, universalidad, estabilidad y simplicidad.

Existe una marcada relación entre la medición de la pobreza y las fuentes disponibles. En nuestro caso - un enfoque con dimensiones nacionales- la única posibilidad son los Censos Nacionales de Población, Hogares y Viviendas.

Teniendo presente estas características y limitaciones se elaboró la Tasa de Miseria de los Hogares, una herramienta que procura aproximarse a la identificación y agregación de los hogares en situación de pobreza extrema en los años 1991 y 2001.

\section{La Tasa de Miseria de los Hogares}

Las dimensiones consideradas dentro de la identificación de la miseria son ${ }^{10}$ :

- Vivienda: respecto a la vivienda se puso especial énfasis en la calidad del piso, identificando las viviendas con piso de tierra, el cual de alguna manera evidencia el grado de capitalización que poseen las mismas. Asi-

\footnotetext{
mantiene el equilibrio de los recursos ante el aumento poblacional. Las obras clásicas que exponen estas teorías son: Thomas Malthus (1798): Ensayo sobre el principio de la población; y Ester Boserup (1984): Población y cambio tecnológico. Estudio de las tendencias a largo plazo.

${ }^{10}$ El déficit de consumo alimentario, ya sea por escasez o mala calidad, es quizás el indicador más representativo de la miseria. No obstante, la fuente de información censal no posee información al respecto, por lo cual la selección de las variables incluidas en la tasa de miseria procuraron identificar las carencias extremas usando la fuente censal y aprovechando las ventajas que de ello se deriva.
} 
mismo, constituye también una condición importante respecto a higiene, contaminación, transmisión de vectores infecciosos y salud.

- Agua: el acceso y la calidad del agua constituye un indicador que denota las características de un bien cuya necesidad es prioritaria para la vida. Sostiene Calamante (2007, p. 83) «el desarrollo infantil está vinculado con las condiciones en que se encuentran actualmente los servicios de agua potable y saneamiento», haciendo así referencia al impacto en la salud infantil de la precaria calidad del agua. Asimismo, un hecho tan simple como la mejora en el abastecimiento de agua y la evacuación de las aguas residuales en los últimos años del siglo XIX fue en gran medida responsable de la disminución de la mortalidad por enfermedades diarreicas y entéricas (Mckeown, 1988). En este trabajo se consideró que el servicio de agua manifiesta una situación de miseria cuando el hogar se provee de agua para consumo fuera del terreno de residencia.

- Combustible usado para cocinar: la cédula censal ofrece dos grandes categorías ante la respuesta a esta variable, se distingue entre uso de gas para cocinar (en red, tubo o garrafa) y el uso de leña o carbón. La utilización de este último como principal combustible para cocinar también nos aproxima a la escasa capitalización del hogar en cuanto a bienes y servicios estructurales se refiera. Asimismo pone de manifiesto, ante su escasez, la imposibilidad para dar cocción a los alimentos.

- Educación: la mayoría de los índices de pobreza tienen una componente educativa en su definición. Se consideró manifestación de miseria la presencia en el hogar de al menos un integrante mayor de 12 años (una de las edades límite de la educación obligatoria) que sea analfabeto (que no sepa leer ni escribir).

La presencia de estas cuatro características en el seno del hogar fue una condición excluyente para considerar al hogar en situación de miseria. Es decir, mientras con el método NBI la presencia de una necesidad insatisfecha definía al hogar como pobre, en el caso de la miseria las cuatro características formuladas deben estar cumplidas como un requisito necesario para la identificación de la miseria. Esta característica sumada a la rigurosidad de las variables mencionadas define el grado de extremidad de la pobreza considerada. En este sentido, usando los datos del los Censos Nacionales de Población, Hogares y Viviendas 1991 y 2001, se detectó cuantos hogares en cada departamento reunían estas cuatro características y fueron relacionadas con el total de hogares de cada departamento. 
FIGURA 1

REPÚBLICA ARGENTINA. DISPERSIÓN DEPARTAMENTAL SEGÚN IPMH Y TMH (2001)

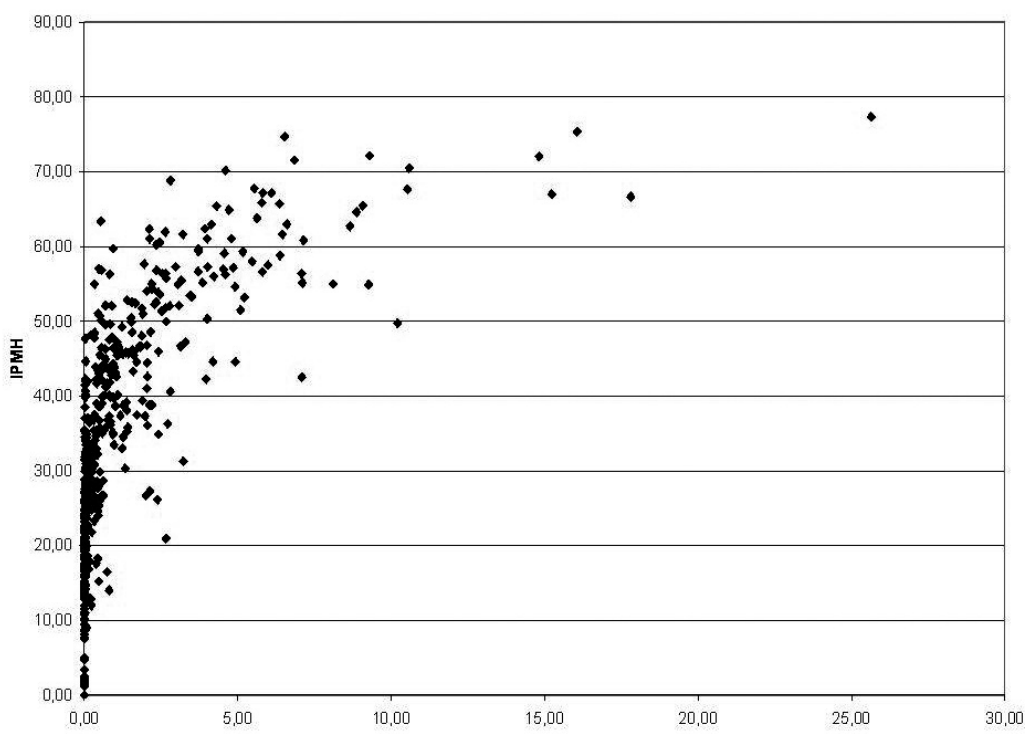

Fuente: Censo Nacional de Población, Hogares y Viviendas 2001.

Elaboración propia.

Asimismo se constató que la TMH y el IPMH tienen una asociación marcada, con un coeficiente de correlación de 0.67. La dispersión que presentan ambas metodologías en 2001 en Argentina puede observarse en la figura 1.

Asimismo, se comprobó la coherencia de la tasa, definiendo niveles de miseria ${ }^{11}$ y relacionándolos con variables no incluidas en la formulación de la tasa, tales como residencia de la población (urbana, rural concentrada y rural dispersa); pertenencia a algún pueblo aborigen; características de la deposición de excretas; tenencia de cocina, computadora y heladera; paredes predominantes de adobe; techos de chapa de cartón, tabla, chapa o paja; y agua para beber y cocinar procedente de río, canal, arroyo o lluvia. Los resultados son coherentes con la formulación de la tasa, existiendo un aumento de la variable

${ }^{11}$ La definición de tales niveles tomó como referencia la distribución por cuartiles de la tasa en los departamentos de Argentina, conteniendo cada nivel el 25\% de los departamentos. 
considerada ante un aumento en el nivel de miseria (cuadro 1). Asimismo presenta coherencia también la distribución de los hogares según valores de la TMH (figura 2), donde se observa que la mayor parte de los hogares de Argentina no forman parte del universo de la miseria, mientras los que si integran dicho universo presentan una tendencia descendente a medida que se intensifican las carencias.

\section{CuAdro 1}

REPÚBLICA ARGENTINA. NIVELES DE TMH Y VARIABLES CENSALES

NO CONSIDERADOS EN LA FORMULACIÓN DE LA TASA. VALORES PORCENTUALES. 2001

\section{Nivel 1 Nivel 2 Nivel $3 \quad$ Nivel 4}

Población en localidades urbanas

$\begin{array}{rrrr}97,4 & 92,3 & 75,6 & 61,4 \\ 1,1 & 3,1 & 7,1 & 9,1 \\ 1,5 & 4,5 & 17,3 & 29,5 \\ 2,0 & 2,1 & 2,2 & 5,0\end{array}$

Población rural concentrada.

Población rural dispersa.

Hogares aborígenes$$
2,1
$$

Hogares sin heladera

Hogares sin cocina

1,0

Hogares sin computadora 57,1

67,3

$74,9 \quad 79,2$

Hogares con paredes de adobe

$$
0,3
$$

1,8

$5,4 \quad 10,3$

Hogares con techos de chapa de cartón o caña, tabla o paja

$$
0,6
$$

$8,5 \quad 14,4$

Hogares con agua para beber y cocinar procedente de río, canal, arroyo o lluvia.

Fuente: Censo Nacional de Población, Hogares y Viviendas 2001.

Elaboración propia. 
FIGURA 2

REPÚBLICA ARGENTINA. TASA DE MISERIA DE LOS HOGARES SEGÚN CANTIDAD DE HOGARES (2001)

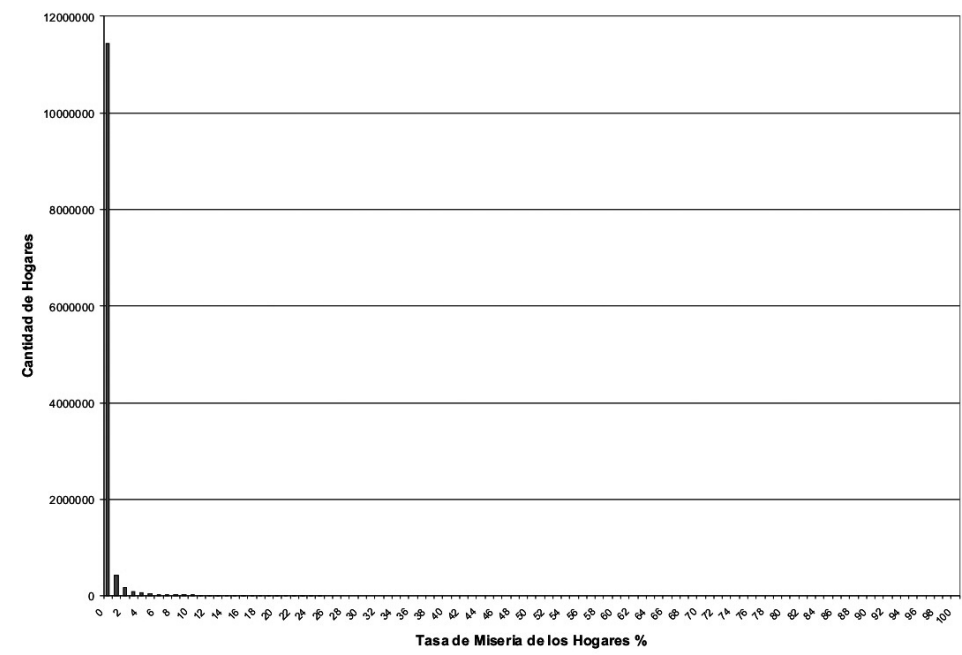

Fuente: Censo Nacional de Población, Hogares y Viviendas 2001.

Elaboración propia.

\section{El marco neoliberal argentino}

Durante el siglo xx Argentina ha sido afectada por continuas crisis. A la crisis del Estado de Bienestar de los años ochenta le continuó la irrupción a partir de la década de los noventa del modelo neoliberal ${ }^{12}$. Este modelo, si bien reconoce algunos antecedentes ya en la década de los setenta con la política económica del Ministro Martínez de Hoz, fue a partir de los noventa cuando fue plenamente implementado en el país. Las principales características del modelo fueron la reorganización del sistema financiero, la precarización del trabajo, la privatización de las empresas públicas y la liberalización de los

12 Plantea Bustelo (1997) las limitaciones durante los años ochenta del Estado de Bienestar para dar solución a los principales problemas sociales, entre ellos la pobreza, pasando de la crisis de este a la producción del «Estado de malestar». Entre las características de este cita la conformación de una sociedad mas dual, donde los estratos medios tienden a desvanecerse, el congelamiento de las perspectivas de movilidad social ascendente, y una caída generalizada de las expectativas relacionadas con el mejoramiento de la calidad de vida. 
mercados. Este modelo, motivado en su implementación por instituciones internacionales como el Fondo Monetario Internacional y el Banco Mundial, intensificó la desigualdad (Gudynas y Villalba Medero, 2006). Un concepto clave que acompañó esta desigualdad fue el del crecimiento económico, entendido como proceso de expansión económica, el cual sería el motor que aseguraría el «desarrollo» del país y permitiría aliviar la pobreza ${ }^{13}$. El efecto «derrame» en el que redundaría un crecimiento económico sin igual nunca llegó a los sectores más carenciados ${ }^{14}$, limitándose solo a un «goteo» e intensificando como nunca antes el crecimiento desmesurado de los llamados «nuevos pobres» (Minujín y Kessler, 1995), y volviendo a los «viejos pobres» o pobres estructurales más pobres aún (Minujín, 1997).

Este modelo llevó consigo, implícita o explícitamente, no solo consecuencias que se manifiestan en el plano económico, sino también en lo político, social y territorial ${ }^{15}$. En este sentido, las decisiones que se tomaron crearon condiciones de inestabilidad, corrupción, aumento de la desocupación y concentración de la riqueza.

\section{El territorio del Norte Grande Argentino. Contexto de miseria persistente y aumento de la concentración en 2001}

Las nueve provincias del Norte Grande Argentino (NGA) cubren alrededor de $760.000 \mathrm{~km}^{2}$, lo cual representa el $27.5 \%$ de la superficie nacional, albergando en su interior hacia 2001 al $20.7 \%$ de la población argentina ${ }^{16}$.

Son numerosos los estudios sobre el territorio y la pobreza del NGA, entre otros se destacan los trabajos de Bolsi (2004), Bolsi y Meichtry (2006), Bolsi, Paolasso y Longhi (2006), Bolsi (2007) y Bolsi, Longhi, Meichtry y Paolasso

13 Plantean Salama y Valier (1996) que la pobreza tiene más que ver con cuestiones de distribución que con carencias de recursos; sostienen que es más sensato pensar que una mejor distribución mejoraría la trayectoria de crecimiento económico, que confiar en la relación inversa.

${ }^{14}$ Cf. Bustelo (1997); Borón (2000, 2004); Neffa (2005) y Feliz (2005).

15 Con respecto a esta última característica, Gudynas (2005) plantea que el Estado-Nación, bajo el orden neoliberal, no puede controlar todo su territorio, concentrándose en los sitios vinculados a la economía global. El Norte Grande Argentino se convirtió así en un territorio fragmentado y relegado del crecimiento económico experimentado por el país durante los noventa. Sin embargo esta condición de marginalidad del NGA no solo se limita a la última década, sino que fue una característica persistente, como lo demuestran Bolsi, Longhi, Meichtry y Paolasso (2009), al menos durante todo el siglo xx.

${ }^{16}$ Integran este territorio las provincias de Tucumán, Jujuy, Salta, Catamarca, Santiago del Estero, Chaco, Corrientes, Formosa y Misiones. 
(2009). En ellos se ha puesto de manifiesto el carácter marginal del NGA y la débil participación del territorio en la generación de riqueza a lo largo del siglo xx.

Los autores reseñados señalan dos grandes pulsaciones económicas que incidieron sobre el territorio, la primera de ellas sobre finales del siglo xIX y comienzos del siglo xx, involucrada con la consolidación del capitalismo y la instalación de las grandes agroindustrias del norte ${ }^{17}$; la segunda pulsación está relacionada con la «pampeanización» del Norte, la cual muestra los primeros indicios hacia 1960 profundizándose entre 1970 y 2000. La pobreza del Norte Grande estaría relacionada con las características de esas pulsaciones, con el territorio, con las persistencias y con las articulaciones de los constructores del territorio (Bolsi, 2007).

Sobre un territorio complejo, donde residen diversas sociedades que mostraron distintos grados de articulación, se consolidó a fines del siglo XIX el capitalismo, generando «residuos» o «víctimas colaterales del progreso» (Bauman, 2005) ${ }^{18}$.

Bolsi (2007) se pregunta cual es la causa que posibilitó que el liberalismo genere en la Pampa Húmeda, el territorio más rico del país, y, en el Norte, un territorio dominado por las carencias. Conjetura que las respuestas se localizan necesariamente en el ámbito cultural, reconociendo la importancia del sistema de articulaciones desarrollado entre las sociedades del Norte (donde lo tradicional desempeña un papel importante) y las sucesivas pulsaciones mencionadas arriba. Destaca así la coexistencia en el NGA de por lo menos dos grandes grupos, cada uno de ellos con su propio «conjunto central de cómo son y como deben ser las cosas» (Benedict, 1939). Estos dos grandes grupos son, por un lado, la sociedad moderna y capitalista y, por otro, la sociedad tradicional. Ambas mostraron distintos grados de articulación con las pulsaciones económicas, definiendo un problema social casi único en el país ${ }^{19}$.

Este territorio complejo, variado, de estructura productiva débil y dominado por las carencias, fue receptor durante los noventa - al igual que el resto del país- del modelo político económico neoliberal, cuestión que agravó la tradicional condición de pobreza.

${ }^{17}$ Entre dichas actividades se destacan el caso de la agroindustria yerbatera en CorrientesMisiones, el algodón el Chaco y la caña de azúcar en Tucumán, Salta y Jujuy.

18 Estos «residuos» están relacionados con la presencia de poblaciones indígenas y de campesinos, ambas involucradas con los llamados núcleos duros de la pobreza regional (Bolsi y Paolasso, 2009).

${ }^{19}$ Plantea Bolsi (2007) que no solo se trata del problema riqueza/pobreza; los contrastes del NGA con el resto de Argentina involucran también la edad de la población, la alta cuota de carga económica, la natalidad, la mortalidad infantil, cuyas diferencias aproximan al NGA mas al universo latinoamericano que al pampeano. 
El nuevo gobierno asumido en 1989 impuso una combinación de políticas de estabilización y de reformas estructurales caracterizadas por su profundidad y audacia. Ante cada crisis, el presidente no dudó en ratificar los lineamientos enviados desde el exterior, es decir, la implementación de la receta neoliberal, caracterizada por la doble propuesta de reforma y ajuste ${ }^{20}$.

En este contexto la distribución del ingreso adquirió un carácter regresivo producto del sendero por el cual transitaba la economía. Los sectores de menos ingresos son los que más terreno han perdido desde la implementación de las reformas; el sector medio tuvo un boom de consumo y crédito favorecido por el fuerte ingreso neto de capitales externos en la primera mitad de la década y vio esfumar dicha ventaja en la segunda mitad; y por último un sector en la cúspide que escamoteó los efectos de la crisis e incluso incrementó en términos porcentuales sus ingresos. El cuadro 2 exhibe la distribución del ingreso en el país según deciles para los años 1991, 1994 y 1998. Se observa el creciente proceso de concentración del ingreso en cada vez menos población.

CuAdro 2

ARGENTINA. DISTRIBUCIÓN PORCENTUAL DEL INGRESO DE LA POBLACIÓN ACTIVA SEGÚN DECILES.1991, 1994 Y 1998

\begin{tabular}{cccc}
\hline DECILES & 1991 & 1994 & 1998 \\
\hline 1 & 0.14 & 0.00 & 0.00 \\
2 & 2.88 & 1.73 & 0.56 \\
3 & 4.56 & 4.24 & 3.32 \\
4 & 5.40 & 5.47 & 5.01 \\
5 & 6.58 & 6.76 & 6.35 \\
6 & 7.74 & 8.01 & 7.87 \\
7 & 9.56 & 9.63 & 9.56 \\
8 & 11.99 & 12.19 & 12.12 \\
9 & 16.22 & 16.34 & 16.75 \\
10 & 34.93 & 35.63 & 38.46 \\
\hline
\end{tabular}

Fuente: Tomado de Gambina (2001, p. 206).

20 Tal recetario se enmarca dentro del denominado Consenso de Washington; según esta nueva fe, las crisis del Estado de Bienestar se superarían con la apertura de la economía, la eliminación de controles al flujo de los capitales financieros, y la supresión de la protección y otros subsidios estatales. El argumento del Consenso de Washington vincula directamente a la intervención del Estado en la economía como el origen de todos los desequilibrios. 
En el plano territorial la década del noventa fue testigo del último de los cambios importantes en la estructura y en la superficie agropecuaria del NGA debido a la fuerte expansión de los cultivos de cereales y oleaginosas ${ }^{21}$. La soja fue el caso más importante, expandiéndose principalmente en Salta, Santiago del Estero, Chaco y Tucumán. El mundo rural fue atacado en casi todos sus frentes, afectando principalmente a los sectores más frágiles: cambios en los vínculos laborales, precarización laboral creciente de los trabajadores dependientes del agro, y expansión del contratismo fueron algunos de los elementos que incrementaron la exclusión (Bolsi, 2004).

Así, las prácticas neoliberales encontraron en el NGA una sociedad y un territorio vulnerable. El NGA conformó tanto en 1991 como en 2001 el área mas crítica respecto a la concentración de miseria del país. Diversas metodologías de medición de la pobreza ponen de manifiesto esta situación, pero un indicador como la Tasa de Miseria de los Hogares vuelve notoriamente visible el grado de carencia y desprotección en el que se encuentra la población del NGA. En este sentido el contraste que presenta la miseria del NGA respecto al resto del país es evidente. Los mapas de las figuras 3 y 4 muestran la distribución espacial de la miseria en los años 1991 y 2001. Se observa la persistencia del fenómeno y el aumento del contraste hacia finales de la década.

Los mapas son elocuentes. En 1991 existían en el país 73643 hogares en situación de miseria, de los cuales el 77.3 \% se hallaban en el NGA. En 2001 la cantidad de hogares en esta situación disminuyó a 40936, sin embargo la proporción de los que se localizan en el NGA aumentó a un 83.8\%, volviendo mas crítica la asimetría existente en el país. Esta situación puede observarse claramente en el cuadro 3.

\section{CUADRO 3}

NORTE GRANDE ARGENTINO Y RESTO DEL PAÍS. PROPORCIÓN DE HOGARES EN SITUACIÓN DE MISERIA. 1991/2001

\begin{tabular}{ccc} 
& Norte Grande Argentino & Resto del país \\
\hline 1991 & $77.3 \%$ & $22.7 \%$ \\
2001 & $83.8 \%$ & $16.2 \%$ \\
\hline
\end{tabular}

Fuente: Censos Nacionales de Población, Hogares y Viviendas 1991 y 2001.Elaboración propia.

${ }^{21}$ Dicho proceso adquirió la mayor envergadura, no obstante también crecieron durante la década ciertos cultivos industriales, tales como el olivo en Catamarca y el citrus en Tucumán, como así también se incrementaron en el territorio las hortalizas y algunos frutales (frutillas especialmente). 
FIGURA 3

REPÚBLICA ARGENTINA. DISTRIBUCIÓN DEPARTAMENTAL DE HOGARES EN SITUACIÓN DE MISERIA. 1991

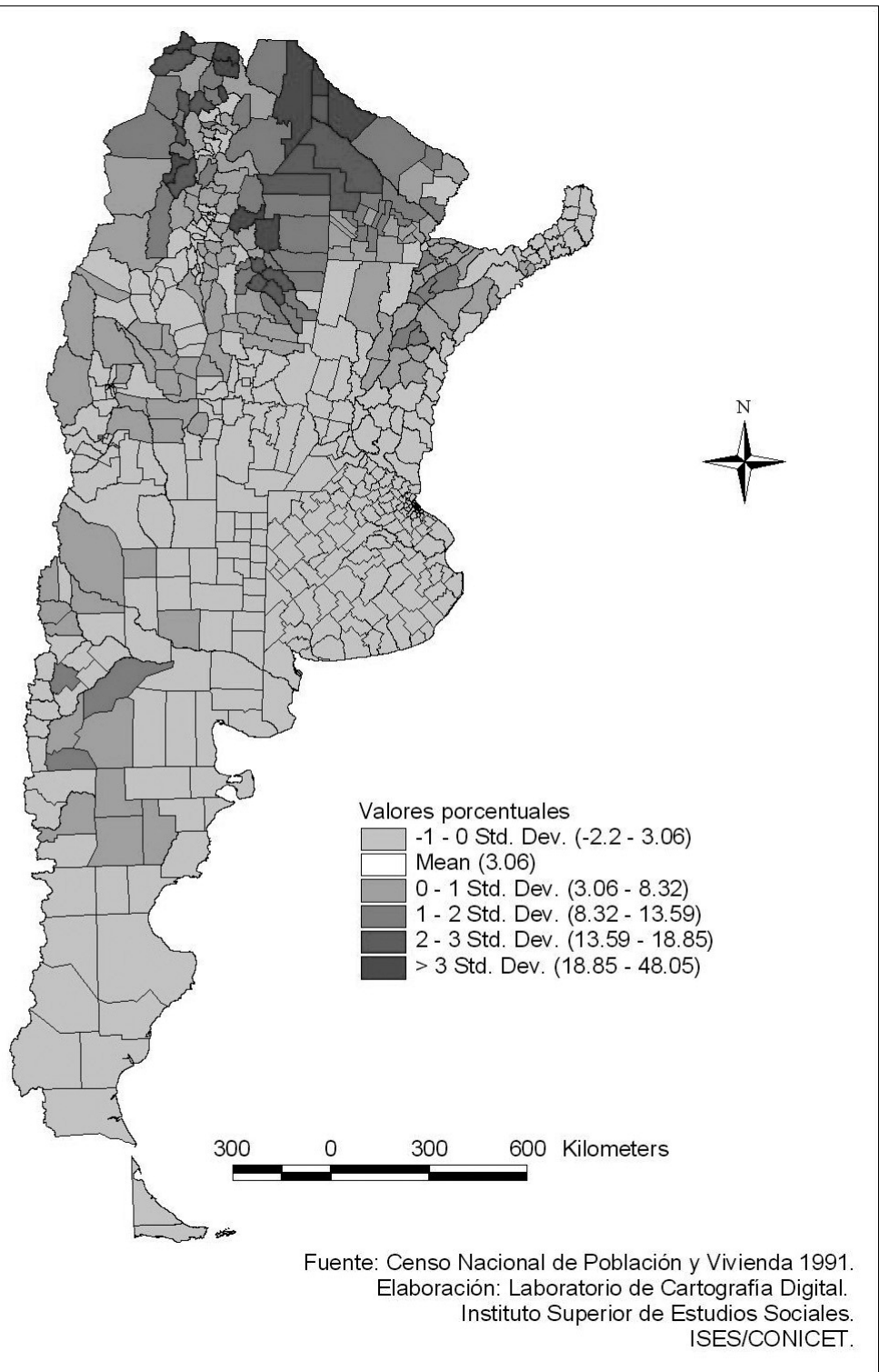

Estudios Geográficos, Vol. LXXII, 271, pp. 505-533, julio-diciembre 2011 ISSN: 0014-1496, eISSN: 1988-8546, doi: 10.3989/estgeogr.201120 
FIGURA 4

REPÚBLICA ARGENTINA. DISTRIBUCIÓN DEPARTAMENTAL DE HOGARES EN SITUACIÓN DE MISERIA. 2001

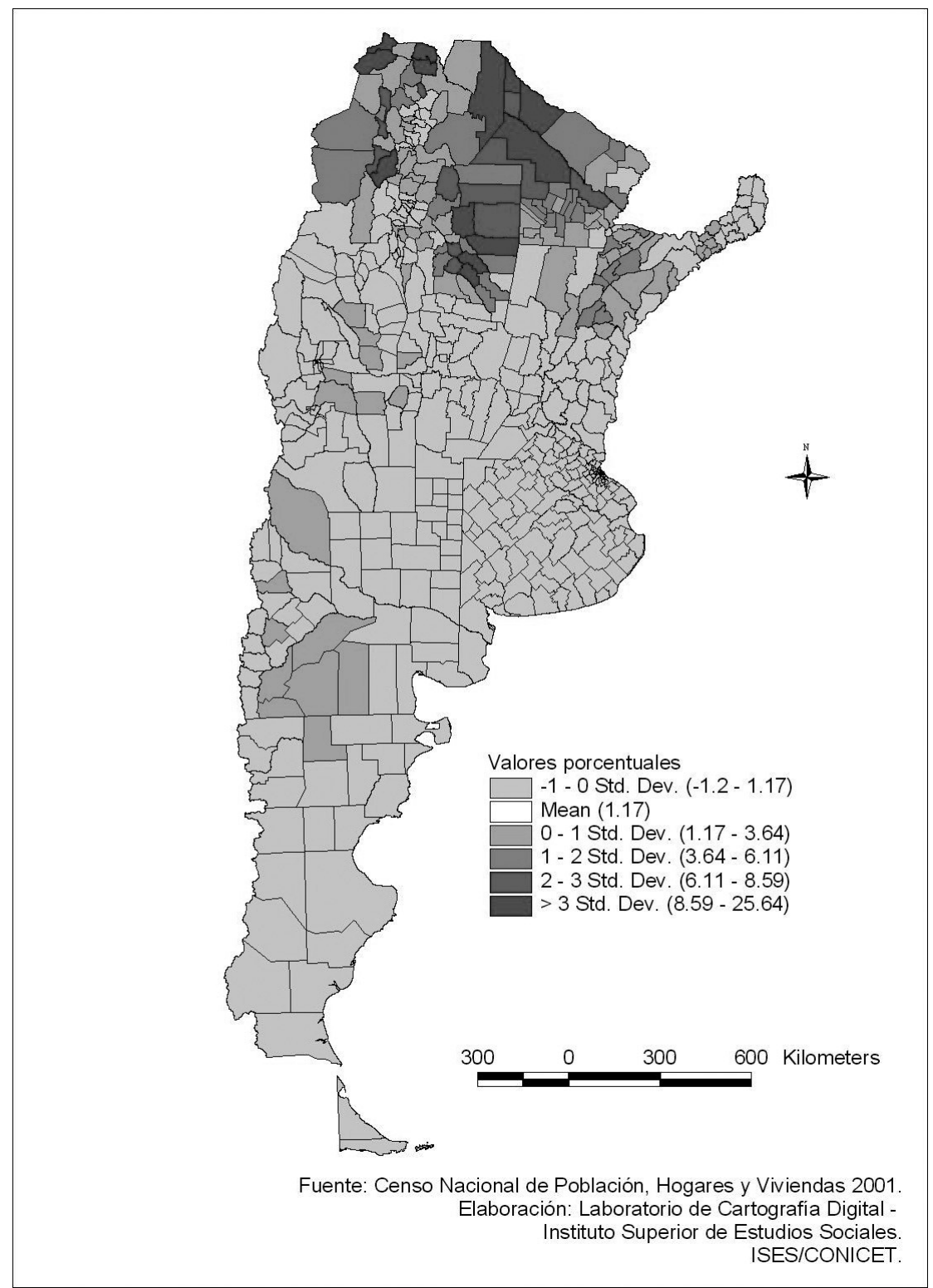

Estudios Geográficos, Vol. LXXII, 271, pp. 505-533, julio-diciembre 2011 ISSN: 0014-1496, eISSN: 1988-8546, doi: 10.3989/estgeogr.201120 
Si bien se observa un proceso de disminución de la miseria —notorio incluso en algunos casos 22 - tal proceso tuvo mayor importancia en el resto del país, logrando en el NGA un ascenso en la concentración de hogares en situación de miseria igual al 6.5\%.

En el interior del NGA las provincias de Chaco, Formosa y Santiago del Estero concentran tanto en 1991 como en 2001 las mayores proporciones de hogares en situación de miseria del país, representando en conjunto el $36.2 \%$ en 1991 y el $46.3 \%$ en 2001. Esta condición de aumento de la concentración es similar - aunque más intensificada - a la observada en el NGA. Coincide asimismo en el año 2001 con una crisis de magnitudes significativas y desconocidas en la historia argentina, constituyendo para Rapoport (2004) la mayor crisis de la historia nacional.

Es notorio también el deterioro en el que se encuentran el resto de las provincias del NGA, las cuales mantienen las mayores proporciones de miseria respecto al resto de las jurisdicciones del país, como puede observarse en la figura 5.

\section{FIGURA 5}

PROVINCIAS ARGENTINAS. TASA DE MISERIA DE LOS HOGARES. 1991 Y 2001

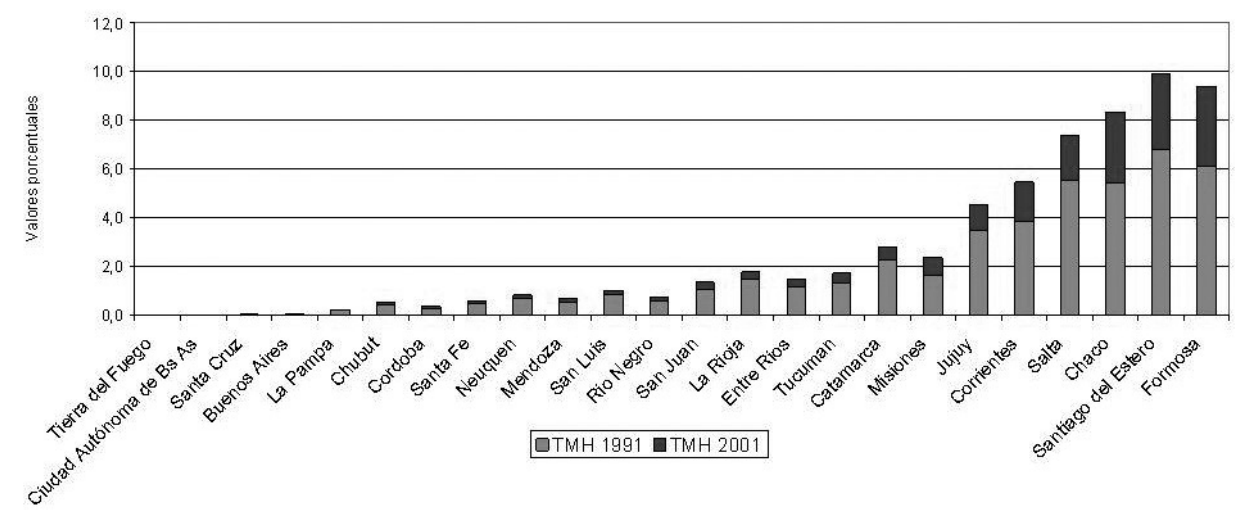

Fuente: Censo Nacional de Población y Vivienda (2001).

Elaboración propia.

22 El departamento Santa Victoria (Salta) pasó de tener la mayor TMH del país igual a 48\% en 1991, a una del 15\% en 2001, constituyendo la jurisdicción que mayor descenso relativo operó. 
FIGURA 6

REPÚBLICA ARGENTINA. TIPOLOGÍA DEPARTAMENTAL SEGÚN VARIACIONES DE LA TMH. 1991 - 2001

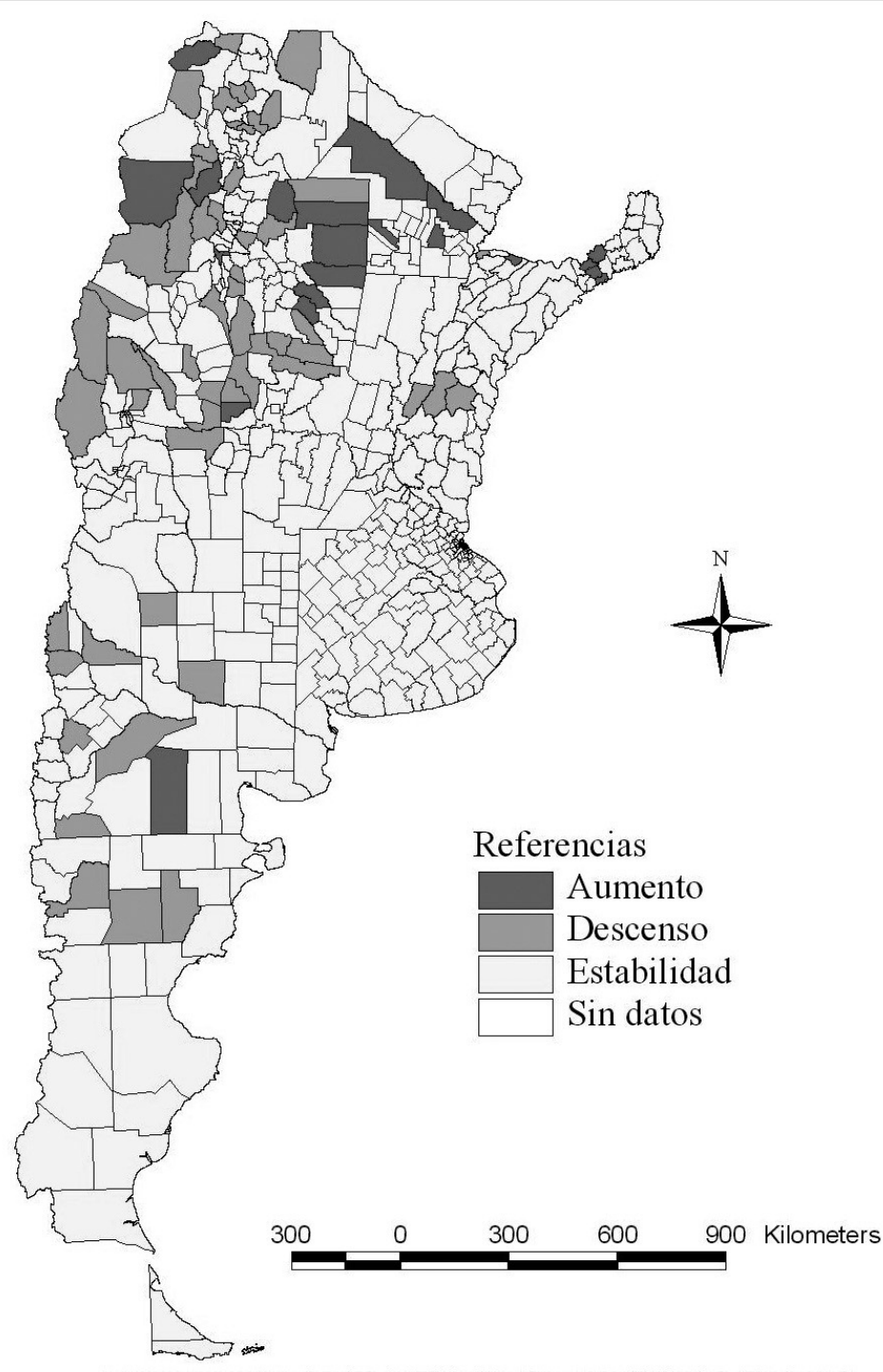

Fuente: Censos Nacionales de Población, Hogares y Viviendas 1991 y 2001. Elaboración: Laboratorio de Cartografia Digital. Instituto Superior de Estudios Sociales. UNT - CONICET.

Estudios Geográficos, Vol. LXXII, 271, pp. 505-533, julio-diciembre 2011 ISSN: 0014-1496, eISSN: 1988-8546, doi: 10.3989/estgeogr.201120 
Respecto a las variaciones 1991-2001 en la distribución espacial de la TMH puede observarse en el mapa de la figura 6 la estabilidad como el rasgo dominante, alcanzando al 91.9\% de la población del país según el Censo Nacional de Población, hogares y Viviendas $2001^{23}$. El aumento de la TMH se concentra fundamentalmente en departamentos del NGA e involucra al $1.3 \%$ de la población argentina, en tanto el descenso no presenta un patrón claro de distribución, e incluye al $2.6 \%$ de la población. El resto de la población corresponde a jurisdicciones que no existían en el año 1991.

\section{Consideraciones finales}

A pesar de los avances notables que se lograron sobre el problema de la pobreza, se trata de un hecho social que muy a menudo parece ser inasible; la carga ideológica inherente al concepto y la alta complejidad del hecho definen un universo con caracteres difusos y contradictorios (Bolsi y Paolasso, 2009). El presente análisis estuvo involucrado con la idea de que poco puede comprenderse sobre la pobreza sin tratar su distribución espacial. En este contexto, el problema de la identificación de los pobres, la distribución espacial del fenómeno como el de sus variaciones espaciales no ha ocupado un interés principal en las ciencias sociales. Ambas manifestaciones constituyen una interesante puerta de entrada al conocimiento del problema, ya que permite identificar no solo a los hogares pobres, sino también sus características y las sociedades involucradas con el universo detectado. Las preguntas ¿dónde están? y ¿quiénes son los pobres? encontrarían de esta manera respuestas. El análisis adquiere particular interés en el caso argentino tratándose de la década de los noventa, periodo en el cual el modelo neoliberal fue aplicado en todas sus dimensiones en el país.

Una valiosa herramienta de medición de la pobreza fue el Índice de Privación Material de los Hogares (IPMH). Sin embargo, solo pudo ser utilizado - de acuerdo con las variables que lo componen- en el año 2001. Por esta razón, dados los objetivos comparativos y la propuesta de la investigación, fue necesaria la elaboración de un nuevo indicador de la pobreza que permita la comparación en ambos fechas. La Tasa de Miseria de los Hogares (TMH) solu-

${ }^{23}$ Para elaborar la figura 6 se identificó la categoría que ocupaba cada departamento en los años 1991 y 2001, a partir de la comparación se detectaron las variaciones. La categoría que ocupa cada departamento estuvo relacionada con el valor promedio y las desviaciones estándar en cada distribución. 


\section{FIGURA 7}

NORTE GRANDE ARGENTINO. IMÁGENES QUE EXHIBEN ALGUNAS PRIVACIONES DE SU POBLACIÓN. 2004
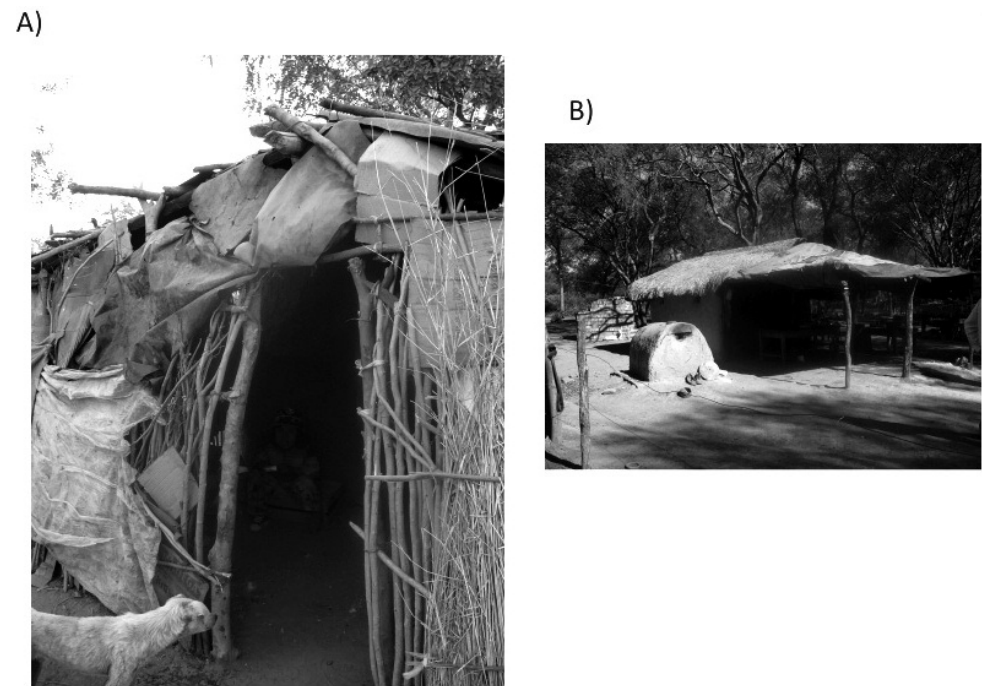

C)

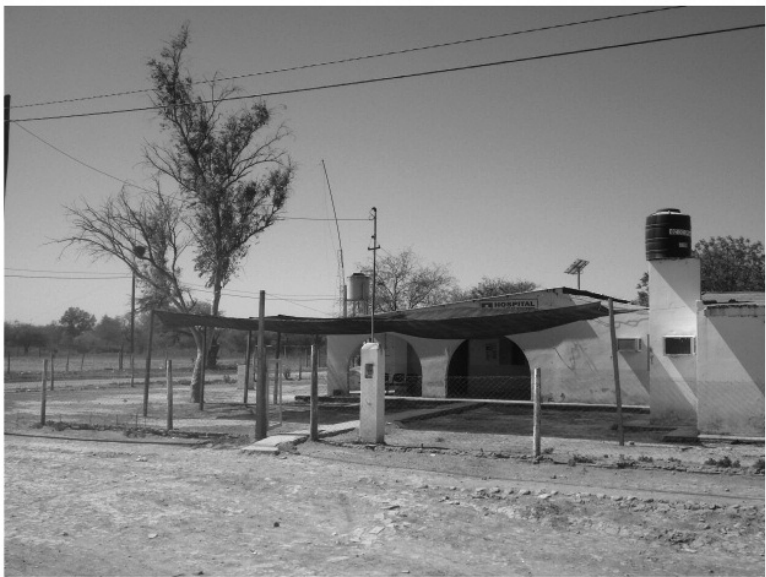

A) Vivienda Wichí en Las Lomitas (Formosa)

B) Vivienda campesina en el oeste chaqueño (Departamento General Güemes)

C) Hospital en el área campesina de Santiago del Estero. (Departamento Figueroa) Fotografías: Fernando Longhi.

Estudios Geográficos, Vol. LXXII, 271, pp. 505-533, julio-diciembre 2011

ISSN: 0014-1496, eISSN: 1988-8546, doi: 10.3989/estgeogr.201120 
cionó estos problemas, mostrando marcada asociación con el IPMH y siendo coherente y consistente en su formulación.

Pudo observarse mediante su aplicación dos procesos que marcan las asimetrías entre el Norte Grande Argentino y el resto del país: concentración de la miseria y aumento de dicha concentración hacia fines de la década en el territorio norteño. Quizás el año 2001 —asociado con la crisis socio-políticoeconómica más importante de la historia argentina- señale de manera más precisa esta cuestión. En este sentido, a comienzos del siglo xxi la extensión y magnitud que alcanza la pobreza extrema entre los argentinos del Norte indica una de las problemáticas sociales más relevantes en la actualidad; la figura 7 permite distinguir, a partir del análisis fotográfico, la severidad de las privaciones en las poblaciones norteñas. El aumento observado en las variaciones de la miseria junto a la concentración detectada aproxima el territorio del NGA a perfiles más similares al universo latinoamericano que al nacional, definiendo un grado de fragmentación territorial casi único en el país.

Los pronósticos no son alentadores, las distancias entre ambos territorios se vuelven más notorias. Si bien operó un descenso de la cantidad de hogares en situación de miseria pudo observarse que tal comportamiento se restringió al resto del país, siendo el aumento de la miseria el comportamiento dominante en los departamentos del NGA.

Se considera que dicho conocimiento debería formar parte de una política de estado específica para las sociedades del Norte Grande Argentino, teniendo presente el condimento cultural relacionado con las poblaciones aborígenes y campesinas que habitan dicho territorio.

Recibido: 10/02/2011

Aceptado: 09/05/2011

\section{BiBLIOGRAFÍA}

Altimir, O. (1979): La dimensión de la pobreza en América Latina. Santiago de Chile, CEPAL, Cuadernos de la CEPAL, 27.

Altvater, E. (2007): "Hambre, subdesarrollo y medio ambiente. Temas de Josué de Castro en tiempos de globalización”. Realidad Económica, 226, IADE, pp. 79-100.

Álvarez, G. (2002): "Capacidad económica de los hogares. Una aproximación censal a la insuficiencia de ingresos". Notas de Población, 74, pp. 213-250.

Arriagada, I. (2005): "Dimensiones de la pobreza y políticas desde una perspectiva de género". Revista de la CEPAL, 85, pp. 101-113. 
Bauman, Z. (2005): Vidas desperdiciadas: la modernidad y sus parias. Buenos Aires, Paidós.

Benedict, R. (1939): El hombre y la cultura. Buenos Aires, Sudamericana.

Bolsi, A. (2004): "Pobreza y territorio en el Norte Grande Argentino". I Congreso de la Asociación Latino-Americana de Población. Caxambú, 18-20 de septiembre de 2004.

Bolsi, A. (2007): "El mito de la opulencia argentina: territorio y pobreza en el Norte Grande Argentino". Actas Latinoamericanas de Varsovia, 30, pp. 189-206.

Bolsi, A. y Meichtry, N. (2006): "Economía de mercado y sociedades tradicionales en la generación de la pobreza en el Norte Grande Argentino". Estudios, 19, pp. 65-89.

Bolsi, A. y Paolasso, P. (2009): Geografía de la pobreza en el Norte Grande Argentino. San Miguel de Tucumán, PNDU-UNT.

Bolsi, A.; Longhi, F; Meichtry, N. y Paolasso, P. (2009): “Ámbito regional. Interrogantes y conjeturas. El territorio del Norte Grande Argentino como contexto de la pobreza", en A. Bolsi y P. Paolasso (comps.): Geografía de la pobreza en el Norte Grande Argentino. San Miguel de Tucumán, PNDU-UNT, pp. 123-171.

Bolsi, A.; Paolasso, P. y Longhi, F. (2006) "El Norte Grande Argentino entre el progreso y la pobreza”. Población y Sociedad, 12-13, pp. 227-266.

Boltvinik, J. (1990): Pobreza y necesidades básicas. Conceptos y métodos de medición. Caracas, PNDU.

Borón, A. (2000): Tras el búho de Minerva. Mercado contra democracia en el capitalismo de fin de siglo. Buenos Aires, CLACSO-Fondo de Cultura Económica.

Borón, A. (2004): Estado, capitalismo y democracia en América Latina. Buenos Aires, CLACSO.

Bustelo, E. (1997): "La producción del Estado de Malestar. Ajuste y política social en América Latina”, en A. Minujín et al.: Cuesta abajo. Los nuevos pobres: efectos de la crisis en la sociedad argentina. Buenos Aires, UNICEF-LOSADA.

Calamante, A. (2007): "Saneamiento básico, agua potable y salud pública", en J. Colombo (ed.): Pobreza y desarrollo infantil. Una contribución multidisciplinaria. Buenos Aires, Paidós, pp. 83-94.

Castro, J. de (1962): Geopolítica del hambre. Ensayo sobre los problemas alimentarios y demográficos del mundo. Oslo, Mathiensen-Eidsvold Vaerk.

Córdoba Ordóñez, J. y García Alvarado, J. (1991): Geografía de la pobreza y la desigualdad. Madrid, Síntesis.

Feliz, M. (2005): "La reforma económica como instrumento de disciplinamiento social: la economía política de las políticas contra la pobreza y la desigualdad en Argentina en los 90", en S. Álvarez Leguizamón (comp.): Trabajo y producción de pobreza en Latinoamérica y el Caribe. Estructura, discurso y actores. Buenos Aires, CLACSO, pp. 240-274.

Ferullo, H. (2009): "Sobre los conceptos de pobreza y subdesarrollo en el pensamiento económico moderno. La pobreza de la teoría económica tradicional", en A. Bolsi y P. Paolasso (comps.): Geografía de la pobreza en el Norte Grande Argentino. San Miguel de Tucumán, PNDU - UNT, pp. 41-52. 
Gasparini, L.; Marchionni, M. y Sosa W. (2001): La distribución del ingreso en la Argentina. Evidencia, determinantes y políticas. La Plata, Universidad Nacional de la Plata-Fundación de Investigaciones Económicas Latinoamericanas.

Giarrizzo, V. (2007): "Pobreza subjetiva en argentina. Construcción de indicadores de bienestar económico"; tesis de doctorado. Buenos Aires, Doctorado en Economía, Universidad de Buenos Aires. (No publicado).

Gómez, A.; Mario, S. y Olmos, F. (2003): "Índice de privación material de los hogares (IPMH). Desarrollo y aplicación con datos del Censo Nacional de población, Hogares y Vivienda 2001". VII Jornadas de la Asociación Argentina de Estudios de Población, Tafí del Valle.

González, H. (1997): "El sujeto de la pobreza: un problema de la teoría social", en A. Minujín et al. (comp.): Cuesta abajo. Los nuevos pobres: efectos de la crisis en la sociedad argentina. Buenos Aires, Unicef-Losada, pp. 285-297.

Gudynas, E. (2005): "Geografías fragmentadas: sitios globalizados, áreas relegadas". Revista del Sur, 160, pp. 3-13.

Gudynas, E. y Villalba Medero, C. (2006): “Crecimiento económico y desarrollo: una persistente confusión”. Revista del Sur, 165, pp. 3-12.

Kaztman, R. (1996): "Virtudes y limitaciones de los mapas censales de carencias críticas". Revista de la CEPAL, 58, pp. 23-32.

Maslow, A. (1970; 1954): Motivation and personality. Nueva York, Harper.

Mckeown, T. (1988): Los orígenes de las enfermedades humanas. Barcelona, Crítica.

Minujín, A. (1997): "En la rodada", en A. Minujín et al. (comps.): Cuesta abajo. Los nuevos pobres: efectos de la crisis en la sociedad argentina. Buenos Aires, Unicef-Losada, pp. 15-44.

Minujín, A. y Kessler, G. (1995): La Nueva Pobreza en Argentina. Buenos Aires, Planeta.

Moreno, M. (1995): "La pobreza: una medición en busca de su contenido conceptual", en III Jornadas Argentinas de Estudios de Población. Santa Rosa.

Naciones Unidas (1961): Definición y medición internacional del nivel de vida. Nueva York, Naciones Unidas.

Neffa, J. (2005): "Pobreza y producción de la pobreza en Latinoamérica y el Caribe", en S. Álvarez Leguizamón (comp.), Trabajo y producción de pobreza en Latinoamérica y el Caribe. Estructura, discurso y actores. Buenos Aires, CLACSO, pp. 193-208.

Nun, J. (1969): "Superpoblación relativa, ejército industrial de reserva y masa marginal". Revista Latinoamericana de Sociología, 5/2, pp. 178-236.

Nun, J. (2001): Marginalidad y exclusión social. Buenos Aires, Fondo de Cultura Económica.

Rapoport, M. (2004): "Notas para una comparación entre la crisis argentina actual, la de 1890 y la de 1930", en R. Boyer y J. Neffa (coords.): La economía argentina y su crisis (1976-2001): visiones institucionalistas y regulacionistas. Buenos Aires, Miño y Dávila, pp. 31-38.

Reyes Romano, J. (1996): "Presentación de metodologías aplicadas en países. La experiencia peruana en la construcción del mapa de NBI", en CELADE (comp.): Semi- 
nario sobre información sobre población y pobreza para programas sociales. Lima, CELADE.

Romero González, J. y Pérez Esparcia, J. (1992): Pobreza y desigualdad en los países en desarrollo. Madrid, Síntesis.

Salama, P. y Valier, J. (1996): Neoliberalismo, pobrezas y desigualdades en el tercer mundo. Buenos Aires, Miño y Dávila Editores.

Sauer, C. (1941): "Foreword to historical geography". Annals of the Association of American Geographers, 31, p. 1-24.

Sen, A. (1978): Poverty and famines. An essay on entitlement and deprivation. Oxford, OIT-Clarendon Press.

Sen, A. (1992): Nuevo examen de la desigualdad. Madrid, Alianza.

Sen, A. (1997): Bienestar, justicia y mercado. Barcelona, Paidós.

Sen, A. (2000): Desarrollo y libertad. Buenos Aires, Planeta.

Tissot, S. y Poupeau, F. (2005): "La spattialisation des problèmes sociaux". Actes de la Recherche en Sciences Sociales, 159, pp. 4-9.

Velázquez, G. (2001): Geografía, calidad de vida y fragmentación en la Argentina de los noventa. Análisis regional y departamental utilizando SIG's. Tandil, Centro de Investigaciones Geográficas, Universidad Nacional del Centro de la provincia de Buenos Aires.

\title{
RESUMEN
}

En este trabajo procuramos realizar una aproximación teórica y metodológica a la medición de la pobreza extrema en Argentina en la última década del siglo xx. Se desarrolló para ello la Tasa de Miseria de los Hogares (TMH), la cual, utilizando información de los Censos Nacionales de Población, Hogares y Viviendas, puede ser detectada y representada cartográficamente en Argentina en 1991 y 2001.

Los resultados definen la fragmentación territorial existente entre el territorio del Norte Grande Argentino y el resto del país. Asimismo los pronósticos no son alentadores, se detecta un aumento de dicha fragmentación en los primeros años del siglo XXI.

Palabras Clave: Pobreza; Miseria; Distribución Espacial; Argentina; Norte Grande Argentino.

\begin{abstract}
In this paper conducts a theoretical and methodological approach to the measurement of extreme poverty in Argentina in the last decade of the twentieth century. Was developed for it the Misery Rate of Households (TMH), which, using information from the National Census of Population, Households and Housing, can be detected and map in Argentina in 1991 and 2001.

The results define the territorial fragmentation between the territory of Greater Northern Argentina and the rest of the country. It also forecasts are not encouraging, detected an increase of the fragmentation in the early twenty-first century.
\end{abstract}


KeY Words: Poverty; Misery; Spatial Distribution; Argentina; Norte Grande Argentino.

\section{RÉSUMÉ}

Dans cet article procède à une approche théorique et méthodologique à la mesure de l'extrême pauvreté en Argentine durant la dernière décennie du xx siècle. A été développé pour les taux de pauvreté des ménages (TMH), qui, utilisant les informations du recensement national de population et des logements peuvent être détectés et représenté cartographique en Argentine en 1991 et 2001.

Les résultats définissent la fragmentation territoriale entre le nord du territoire de l'Argentine et le reste du pays. Il a également prévisions ne sont pas encourageantes, provoque une augmentation de la fragmentation dans les premières années de ce siècle.

MотS CLÉs: pauvreté; misère; la répartition spatiale; Argentina, Norte Grande Argentino. 